\title{
Do Categories Have Politics? The languagelaction perspective reconsidered
}

\author{
LUCY SUCHMAN \\ Xerox Palo Alto Research Center, U.S.A.
}

(Received 31 August 1993; in final form 6 September 1993)

\begin{abstract}
Drawing on writings within the CSCW community and on recent social theory, this paper proposes that the adoption of speech act theory as a foundation for system design carries with it an agenda of discipline and control over organization members' actions. I begin with a brief review of the language/action perspective introduced by Winograd, Flores and their colleagues, focusing in particular on the categorization of speakers' intent. I then turn to some observations on the politics of categorization and, with that framework as background, consider the attempt, through THE COORDINATOR, to implement a technological system for intentionaccounting within organizations. Finally, I suggest the implications of the analysis presented in the paper for the politics of CSCW systems design.
\end{abstract}

Key words. Coordination technologies, organizational communications, speech act theory, systems design.

No idea is more provocative in controversies about technology and society than the notion that technical things have political qualities. At issue is the claim that machines, structures, and systems of modern material cuiture can be accurately judged not only for their contributions to efficiency and productivity ... but also for the ways in which they can embody specific forms of power and authority.

Winner 1986 , p. 19.

By teaching people an ontology of linguistic action, grounded in simple, universal distinctions such as those of requesting and promising, we find that they become more aware of these distinctions in their everyday work and life situations. They can simplify their dealings with others, reduce time and effort spent in conversations that do not result in action, and generally manage actions in a less panicked, confused atmosphere.

Flores et al. 1988 , p. 158.

The world has always been in the middle of things, in unruly and practical conversation, full of action and structured by a startling array of actants and of networking and unequal collectives... The shape of my amodem history will have a different geometry, not of progress, but of permanent and multi-patterned interaction through which lives and worlds get built, human and unhuman.

Haraway 1991, p. 11.

\section{Introduction}

Since the inception of CSCW as an explicit research agenda in the early 1980's, a class of systems has been under development that attempt to structure computerbased message systems into tools for the coordination of social action. Some of these have been concerned with affording flexible support for a diverse and changing ensemble of communicative practices (for example COSMOS/Bower and Churcher 1988). Others have been aimed at using system design as a mechanism for the prescription of a priori forms of social behavior. Arguably the most 
influential of the latter efforts has been the language/action perspective of Winograd, Flores and their colleagues and the system, trademarked THE COORDINATOR, designed to implement it. ${ }^{1}$

This paper is an attempt to contribute to a critical re-examination of the place of coordination technologies in $\mathrm{CSCW}$ research and development, in particular that class of technologies that seeks to provide canonical frameworks for the representation and control of everyday communicative practices. Among the latter, I take the language/action perspective of Winograd, Flores et al. and its embodiment in THE COORDINATOR as exemplary. Of particular concern is the problem of how the theories informing such systems conceptualize the structuring of everyday conversation and the dynamics of organizational interaction over time. To anticipate, I will argue that the adoption of speech act theory as a foundation for system design, with its emphasis on the encoding of speakers' intentions into explicit categories, carries with it an agenda of discipline and control over organization members' actions. Alternatively, we might embrace instead something closer to the stance that historian Donna Haraway recommends; namely, an appreciation for and engagement with the specificity, heterogeneity and practicality of organizational life.

My strategy for developing this argument will be to juxtapose what might at first seem unrelated discussions, drawn on the one hand from influential writings within the CSCW community and on the other from recent social theory. Specifically, I begin with a brief review of the language/action perspective introduced by Winograd, Flores and their colleagues, focusing in particular on the place of speech act theory and the categorization of speakers' intent in that perspective. I then turn to some observations on the politics of categorization offered by the sociologist Harvey Sacks, and on disciplinary practice by the philosopher Michel Foucault. The point of this latter move is to look at the place of categorization as an instrument in the control of social relations. With that sociological framework as background, I consider the attempt, through THE COORDINATOR, to implement a technical system for intention-accounting in organizations. Finally, I suggest the implications of the analysis presented for the politics of CSCW systems design.

\section{Speech act theory}

In their book Understanding Computers and Cognition: A New Foundation for Design (1986) Winograd and Flores present speech act theory as the basis for a particular doctrine of communication, and an associated machinery for the training and improvement of members' participation in organizational life. From the language/action perspective they describe, the "ontology" of organizational life

\footnotetext{
1 Both the language/action perspective and THE COORDINATOR have been described in numerous publications. The present discussion relies upon Winograd and Flores 1986, and Flores et al. 1988.
} 
comprises speech acts combined into "recurrent patterns of communication in which language provides the coordination between actions" (1988, p. 156). Through their development of this perspective, speech act theory has come to be a dominant framework for the conceptualization of communicative action within the CSCW community. To understand the underpinnings of that conceptualization requires a closer look at just what speech act theory takes to be its basic premises and what makes those premises compelling for computer research. The two aspects of the theory most relevant to the present argument are a) the premise that language is a form of action and b) the assumption that a science of language/ action requires a formal system of categorization.

The observation that language is social action is due originally to Austin (1962) and the later Wittgenstein (1958), who argue for the impossibility of theorizing language apart from its use. Somewhat paradoxically, however, their observations have been taken by subsequent theorists as grounds for assuming that $a$ theory of language constitutes a theory of action. Rather than setting up as a requirement on theorizing about language/action that it be based in investigations of talk as a form of activity, the observation that language is action has been taken to imply that action is, or can be theorized as, the use of language qua system to get things done. And language taken as a system provides a tractable core phenomenon for disciplines whose theory and methods best equip them for formal systems analysis. The proposition that dealing with language is dealing with action has consequently become a means of extending the scope of such disciplines while requiring little if any change to their organizing premises and practices.

Moreover, as Bowers \& Churcher summarize it "[s]ince Austin, the development of speech act theory has been largely associated with Searle... Searle has been at pains to formalise the notions introduced by Austin, to classify the conditions under which different kinds of speech acts can be appropriately ("felicitously") issued, and to explicate a typology of illocutionary acts. It is Searle's work which has proved particularly influential in CSCW" (op cit., p. 126). Language in this scheme is an instrumentality, a technology employed by the individual to express his or her intentions to others. The taxonomy of utterances that speech act theory after Searle proposes seeks to provide a comprehensive ordering of the available communicative tools, represented as a formalized "grammar of action" (Agre 1993, pp. 26-27).

In response to the popularity of speech act theory a number of cogent critiques have appeared in recent years based on observations drawn from the analysis of actually occurring conversation (see for example Bogen 1991, Bowers \& Churcher 1988, Schegloff 1988, Levinson 1983). These critiques turn on the interactional and circumstantially contingent character of meaning and intention. Briefly, the argument is that speech act theory takes communication as an exchange of speakers-hearers' intent, while conversation analyses underscore the irreducibly interactional structuring of talk. So, for example, conversation analysts have documented the ways in which a speaker's intent is observably shaped 
by the response of hearers over the course of an utterance's (co)production (see for example Goodwin 1981, chpt. 4; Goodwin \& Goodwin 1992, Schegloff 1982). Bowers and Churcher argue that the consequent "radical indeterminacy" of the unfolding course of human interaction presents a problem for any system designed automatically to track an interaction's course by projecting expected or canonically organized sequences. This, they argue, "cannot be ignored by designers of systems for CSCW without unwittingly coercing their users" (op cit, p. 137).

A related criticism of speech act theory turns on the difficulty, for the hearer/analyst, of categorizing the illocutionary force or perlocutionary effect of an utterance given its interactional and contingent character. THE COORDINATOR dispenses with this problem by enrolling speakers themselves in categorizing their utterances with explicit illocutionary tags. As Winograd and Flores explain it:

We are not proposing that a computer can 'understand' speech acts by analyzing natural language utterances... What we propose is to make the user aware of this structure and to provide tools for working with it explicitly. This is being done experimentally in a computer program that we are developing called a 'coordinator', designed for constructing and controlling conversation networks in large-scale distributed electronic communication systems... An individual performs a speech act using THE COORDINATOR by: selecting the illocutionary force from a small set of alternatives (the basic building blocks mentioned above); indicating the propositional content in text; and explicitly entering temporal relationships to other (past and anticipated) acts (1986, p. 159).

So in the face of otherwise intractable uncertainties in accounting for the "illocutionary force" of a given utterance, THE COORDINATOR enlists participants in a coding procedure aimed at making implicit intent explicit. The premise of this procedure is that explicitly identified speech acts are clear, unambiguous, and preferred. ${ }^{2}$ Whether based in the assumption that intent is somehow there already in the utterance and that what is being done is simply to express it, or that left to themselves people will remain vague as to their own intent and that of others and will benefit from the discipline of being pressed for clarity, the strategy of THE COORDINATOR is to remedy the carelessness of organization members regarding their commitments to each other through a technologically-based system of intention-accounting. According to Winograd and Flores the motivation here is explicitly self-improvement:

In their day-to-day being, people are generally not aware of what they are doing. They are simply working, speaking, etc. more or less blind to the pervasiveness of the essential dimensions of commitment. Consequently, there

2 See Bowers 1992, pp. 3-4 for a discussion of the modernist preference for the "clear and distinct" and its relation to agendas of explicitness, formalisation and control. 
exists a domain for education in communicative competence: the fundamental relationships between language and successful action... People's conscious knowledge of their participation in the network of commitment can be reinforced and developed, improving their capacity to act in the domain of language (ibid, p. 162).

The machine thus becomes the instructor, the monitor of one's actions, keeping track of temporal relations and warning of potential breakdowns. It provides as well, of course, a record that can subsequently be invoked by organization members in calling each others' actions to account.

\section{Categorization as discipline}

Speech act theory brings us into the presence of categorization as a basic device for the analytic sciences, including the longstanding search for a science of intentionality. Within recent social science, in particular ethnomethodology, this tradition has been challenged through a conceptually simple but consequentially complex inversion of the status of categorization devices as analytic resources. Briefly, categorization has been taken up not just as a resource for analysts but as part of their topic or subject matter; that is, as a fundamental device by which all members of any society constitute their social order. With this move has come a rich corpus of theorizing and of empirical study about just how they do so (see for example Sacks 1979, Sacks and Schegloff 1979, Schegloff 1972).

In his consideration of members' categorization devices, the sociologist Harvey Sacks was concerned among other things with the role that categorization plays in contests over the control of social identities. As a way in to his analysis we can take a passage from a 1966 lecture published under the title "Hotrodder: A Revolutionary Category" (1979). The problem Sacks sets up for himself in this lecture is to understand what is going on with teenage kids and cars. Sacks himself is working with a piece of transcript, in which kids are talking about the relative likelihood of getting picked up by the police depending on what kind of car you are driving and, within that, just how you are dressed when driving it. Of this bit of talk and its implications Sacks says:

We could work at it by asking such questions as, why do kids go about making up all those typologies of cars - and the typologies they have are really enormously elaborate, and they use those typologies to make assessments of other drivers, and the assessments are not always very nice, as we've seen. Now the question to ask is why do they do it? Aren't the terms that are used before they go to work good enough? And what's the matter with them if they aren't? (ibid, p. 8) 
For my own present purposes, then, what I want to ask is: What is it about speech act theory that makes it so attractive as a way for practitioners of science and systems design to come to grips with organizational communications? Why do computer scientists go about making up all these typologies of interaction? Aren't the typologies used by practitioners themselves before we go to work, as designers, good enough? And what's the matter with them if they aren't?

I have already suggested how a particular interpretation of language as action could contribute to the attractiveness of speech act theory for the system sciences. To get more specifically at the question of categorization, we might begin by asking as Sacks does in relation to kids what it is that categorization provides for those making use of it in some domain of activity. Sacks frames his analysis of "hotrodders" in terms of acts of resistance, specifically how persons assigned to a place in a system of categorization not of their own making, e.g. "teenagers," can develop categories for themselves, e.g. "hotrodders" as, in Sacks' terms, a revolutionary act. That is to say, systems of categorization are ordering devices, used to organize the persons, settings, events or activities by whom they are employed or to which they refer. Non-compliance with the use of a particular category scheme, particularly one imposed from outside, or the adoption of an alternative are in this sense acts of resistance. ${ }^{3}$

If membership categorization is appropriable as a technology of control by some parties over others, acts of resistance involve a taking back of systems of naming and assessment into indigenous categorization schemes developed by the "others" themselves. In Sacks' words 'that means, for example, that they will recognize whether somebody is a member of one or another category, and what that membership takes, and they can do the sanctioning... what's known about hotrodders - what they do with their cars, how they look, how they behave - these are things that hotrodders can enforce on each other hand and defend against nonmembers" (original emphasis ibid. pp. 11-12).

Sacks' analysis identifies the relation of categorization devices to social identity, including assessments of persons' adherence to the moral and aesthetic sensibilities associated with a particular category. It points as well to the ways in which categorization can be taken up as a resource in the development of more elaborated and formalised systems of social control. These systems form a kind of technology whether or not they are literally inscribed in a machine. In Discipline and Punish (1979) Michel Foucault traces the historical development of a figurative machinery of disciplinary practice, the military, and takes as a case in point the soldier, treated

3 Liam Bannon points out that this is part of the wider phenomenon of "naming as a form of control ... the missionaries banning the use of native names and giving natives 'Christian' names to make them lose their sense of history, or the British in Ireland re-naming villages and counties in English terms that did not preserve the original Gaelic meanings, thus disinheriting future generations of their past folklore and roots" (1993, personal communication). Anthropology is replete with further examples, drawn from colonial encounters between European and indigenous cultures throughout the world. 
in the 17 th century as an intrinsically honorable entity whose character was reflected in his bearing, becoming in the 18 th century a technical body to be trained via exercise:

These methods, which made possible the meticulous control of the operations of the body, which assured the constant subjection of its focus and imposed on them a relation of docility-utility, might be called 'disciplines'... The historical moment of the disciplines was the moment when an art of the human body was born... A 'political anatomy,' which was also a 'mechanics of power' .... it defined how one may have a hold over others' bodies, not only so they may do what one wishes, but so that they may operate as one wishes, with the techniques, the speed and the efficiency that one determines. Thus discipline produces subjected and practiced bodies, 'docile' bodies (pp. 137-38).

Foucault further points out that disciplinary practices invariably develop in response to specific problems in the administration of power. With these perspectives in mind, we can return to the idea of taking the categorization devices of speech act theory as a basis for organizational communications. Like many of the cases reviewed by Foucault, this order is to be administered technologically. That is to say, troubles diagnosed as breakdowns in communication are to be addressed through a technological solution involving a new communicative discipline. Speech act theory and its attendant technologies are offered as a remedy to perceived flaws and inadequacies in organization members' communicative practices, by providing an order enforced through the technology. The 20th century then might be seen as a return to the analysis and manipulation of what Foucault calls the 'signifying elements of behaviour,' through the training of the body's intentions as reflected in its talk.

\section{The conversation for action}

To see how the discipline of intention-encoding plays out in the technology of 'THE COORDINATOR we can turn to Winograd and Flores' "theory of management and conversation," centered around the "conversation for action" pictured as Figure 5.1 (1986, p. 65) in their text:

As Winograd and Flores explain this figure in their text:

As an example of conversational analysis we will consider in some detail the network of speech acts that constitute straightforward conversations for action - those in which an interplay of requests and commissives are directed towards explicit cooperative action. This is a useful example both because of its clarity and because it is the basis for computer tools for conducting conversations... 


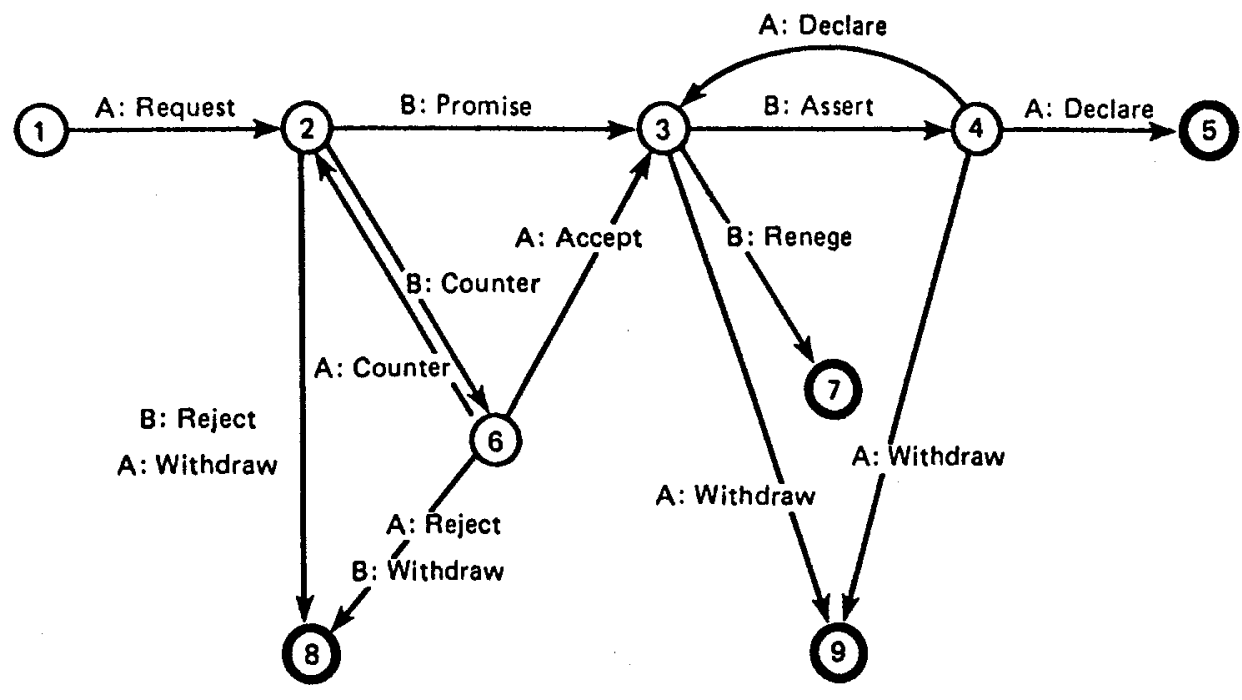

Fig.1. The basic conversation for action. (From Winograd and Flores, 1986, p. 65).

We can plot the basic course of a conversation in a simple diagram like that of Figure 5.1, in which each circle represents a possible state of the conversation and the lines represent speech acts (1986, p. 64, original emphasis).

This picture is central to Winograd and Flores' exposition and, so bears a closer look. In a paper titled "Pictures of Nothing? Visual Construals in Social Theory" (1990) Michael Lynch suggests that representations like that of "the basic conversation for action" as he puts it "both describe the operations of "rationality" and display 'rationalistic commitments'." Such pictures, he explains:

... do not propose to resemble observable phenomena, nor do they present readers with puzzles to be worked out in a visible workspace. Instead, they mobilize formal elements to exhibit and authorize a certain 'impression of rationality'...

This impression of rationality is associated with at least the following formal elements: bounded labels, quasi-causal vectors, and spatial symmetries and equivalences... The spatial separation between the labels contributes to a sense of their conceptual discrimination, and the coherent two-dimensional arrangement provides a unitary 'ground' for linking together the heterogeneous factors... The labels are detached from the relative seamlessness and polysemy of discursive writing, taking on the appearance of stable concepts or even of names for things positioned in space... The entire array of cells and vectors in the picture look somewhat like an electrical wiring diagram; a 
tracing of a tightly contained flow of an homogeneous force from one welldefined component to another (ibid, pp. 20-22).

The picture of the basic conversation for action unifies and mathematizes the phenomena it represents. It works by transforming a set of colloquial expressions into a formal system of categorization that relies upon organization members' willingness to re-formulate their actions in its (now technical) vocabulary (Agre 1993). ${ }^{4}$ Once encapsulated and reduced to the homogeneous black circles and arrows of the diagram the "conversation" is findable anywhere. At the same time, specific occasions of conversation are no longer open to characterization in any other terms.

Winograd and Flores' figure of a conversation claims to be a reduction of the intentional structure of any conversation for action, while also providing the rendering that is required by the computer system, THE COORDINATOR, that they present as a logical consequence of their analysis. In displaying categorical action types and their logical relations, the representation sets up the grounds for just the kind of menu - driven procedures for intention-encoding and accounting that the technology of THE COORDINATOR embodies and prescribes. The Conversation for Action, in contrast to conversations in the course of ongoing activity, is bounded and readyto-hand for translation into the machine. And for management, the machine promises to tame and domesticate, to render rational and controllable the densely structured, heterogeneous texture of organizational life. As Flores et al. put it in the citation with which this paper begins:

By teaching people an ontology of linguistic action, grounded in simple, universal distinctions such as those of requesting and promising, we find that they become more aware of these distinctions in their everyday work and life situations. They can simplify their dealings with others, reduce time and effort spent in conversations that do not result in action, and generally manage actions in a less panicked, confused atmosphere (1988, p. 158).

The assumption that "universal" distinctions such as requesting and promising are simple, however, conflates the simplicity of the category with the subtlety and complexity of the phenomenon categorized. One could imagine by analogy a system of painting that trained artists to follow a "simple" scheme of primary colors. But our sense of artistry in any field is precisely the ability to move, in more and less articulable ways, effectively through the circumstances in which one finds oneself. This is not done through reductions but through complex forms of highly skilled practice, involving an ability to bring past experience to bear in creative ways upon an unfolding situation.

${ }^{4}$ Agre further points out that in the formalization provided by speech act theory the categories employed are not different from members' own so much as different in kind; that is, they are technical renderings of familiar terms. 
There seems something of a contradiction, moreover, between the premise that THE COORDINATOR is a tool for introducing order into an otherwise "panicked, confused atmosphere," and the subsequent statement by Flores $e t$ al. that

[w]e are primarily designing for settings in which the basic parameters of authority, obligation and cooperation are stable... THE COORDINATOR has been most successful in organizations in which the users are relatively confident about their own position and the power they have within it. This does not mean that the organization is democratic or that power relations are equal. It means that there is clarity about what is expected of people and what authority they have (ibid., p. 173).

Rather than being a tool for the collaborative production of social action, in other words, THE COORDINATOR on this account is a tool for the reproduction of an established social order.

Winograd and Flores argue that theory-driven design will produce coherent systems and practices. They report that implementations of THE COORDINATOR have been used to manage large software engineering enterprises, in which they claim the participants report that "by providing a computer tool to maintain the structure of the requests and commitments, they were able to greatly improve productivity" (1986, p. 161). Other reports of THE COORDINATOR use from the field, however, indicate that users selectively appropriate and ignore aspects of the system in an ad hoc fashion (see for example Johnson et al. 1986; Bullen \& Bennett 1990). On the one hand, users' failure in these cases to use the system as intended by its designers could be seen as a failure of the design, or of the compliance of users. On the other hand, it could be taken to reflect the desirability of systems that lend themselves to various ad hoc forms of customization in use (Robinson \& Bannon 1991). The success that THE COORDINATOR has enjoyed, on the latter interpretation, would be understandable less as a result of its theorydriven coherence than of its practical adaptability.

\section{Conclusion}

The language/action perspective takes off from the observation that technologies comprise both artifacts and associated practices. From this it follows that "technology is not the design of physical things. It is the design of practices and possibilities to be realized through artifacts" (Flores et al. 1988, p. 153). What ties together hotrodders, Foucault's soldier and the users of THE COORDINATOR is the belief by others that they must be brought into compliance with a particular conventional order. For technical systems it is the computer scientist (presumably assisted by organizational development consultants and the managers who employ them) who is now cast into the role of designer not only of technical 
systems but of organizations themselves. And implicit in the endeavor of professional organizational design is the premise that organization members, like the components of the technical system, require a strong, knowledgeable hand that orders them, integrates them and brings them effectively into use.

Organizational design from a language/action perspective takes place within the context of a technological imperative that leads inexorably to change and, if done well, to progress. As Flores puts it:

When we accept the fact that computer technology will radically change management and the nature of office work, we can move toward designing that change as an improvement in organizational life (Flores et al. 1988, p. 154).

Before we accept this imperative, however, I would argue that we should subject it to the following questions.

First, what kind of a fact is it "that computer technology will radically change management and the nature of office work"? Computer technology, the directionality and dynamics of change, and the forms of work that are the objects of change are treated as self-evident, homogeneous and naturalized entities. But what if we were to open up this proposition to the uncertainties, heterogeneities and practical expediencies of the categories it invokes? We would need to specify then just what technologies concerned us, and how; whether, or even how those technologies are implicated in what processes of change; just what forms of managerial work we are concerned with and why; and what other forms of work, in what kinds of settings, we assume are getting done.

Second, who are "we"? Form what position do we claim or are we granted rights to design change? In what sense is change designed? From what perspective do we assess the results of our actions as "improving organizational life," and for whom?

Throughout the history of communications technologies within organizations we find the imposition of regimes of action in the name of individual selfimprovement and organizational efficiency (Yates 1989). At the same time, organization members are subjected to ever more elaborated systems of recordkeeping, measurement and accountability. ${ }^{5}$ Instead of the emancipating alternative that Winograd and Flores would seek, they seem to offer yet another technology designed to create order out of "nature" by, as Haraway would put it, "policing her unruly embodiments" (1991, p. 20).

I have proposed that speech act theory offers to system and management sciences a model of the communicative order compatible with the prior commitments of those enterprises - a model of speech that promises a universal basis for

5 For a discussion of the relation of new regimes of "quality" and "empowerment" to such systems, and the ways in which they have become incorporated into the very doing of the work itself, see Agre 1993 and Suchman 1993. 
the design of technologies of accountability. By technologies of accountability I mean systems aimed at the inscription and documentation of actions to which parties are accountable not only in the ethnomethodological sense of that term (Garfinkel and Sacks 1970), but in the sense represented by the bookkeeper's ledger, the record of accounts paid and those still outstanding. If this promise of speech act theory is consistent with the intellectual antecedents and aspirations of system and management science, however, it is also increasingly difficult to maintain in the face of a growing challenge from culturally and historically-based studies of talk as it is specifically located in space and time. Schegloff has stated this challenge in terms of the debate over "context":

This is, to my mind, no escaping the observation that context ... is not like some penthouse to be added after the structure of action has been built out of constitute intentional, logical, syntactic, semantic and pragmatic/speech-acttheoretic bricks. The temporal/sequential context rather supplies the ground on which the whole edifice of action is built (by the participants) in the first instance, and to which it is adapted 'from the ground up' ... (nd. p. 21).

With the emergence of technologies like THE COORDINATOR, this debate is no longer over intellectual terrain alone. The inscription of formal representations of action in technical systems transforms the debate more clearly into a contest over how our relations to each other are ordered and by whom. Sacks' discussion of membership categorization draws our attention to the ways in which categorization devices are devices of social control involving contests between others' claims to the territories inhabited by persons or activities and their own, internally administrered forms of organization. In the case of hotrodders, the move is to develop indigenous categories through which kids are able to claim back ownership of their social identities from the adult world that would claim knowledge of them. In the move to inscribe and encode organization members' intentions, as commitments or otherwise, we find a recent attempt to gain members' compliance with an externally imposed regime of institutional control. Sacks' insight can help us make sense of the abiding interest that those committed to the reproduction of an established institutional order might have in replacing the contested moral grounds of organizational commitment and accountability with a scheme of standardized, universalistic categories, administered through technologies implemented on the desktop.

\section{Acknowledgement}

I am grateful to Phil Agre, Liam Bannon, and Randy Trigg for their comments on an earlier version of this paper. 


\section{References}

Agre, Philip. (1993); From high tech to human tech: on the sudden market for social studies of technology. In the proceedings of the workshop Social science research, technical systems and cooperative work. Paris, France, pp. 17-30.

Austin, J.L. (1962): How To Do Things With Words, Oxford: Clarendon Press.

Bogen, David. (1991): Linguistic Forms and Social Obligations: A critique of the doctrine of literal expression in Searle. In Journal for the Theory of Social Behavior, vol. 21, No. 1, pp. 31-62.

Bowers, John. (1992): The Politics of Formalism. In Contexts of Computer-Mediated Communication ed. M. Lea Hassocks: Harvester.

Bowers, John and Chrucher, John. (1988): Local and Global Structuring of Computer-Mediated Communication. In Proceedings of the ACM Conference in Computer-Supported Cooperative Work, Portland, OR, pp. 125-139.

Bullen, Christine and Bennett, John. (1990): Learning from user experience with groupware. In Proceedings of the ACM Conference on Computer-Supported Cooperative Work, Los Angeles, CA, pp. 291-302.

Duranti, Alessandro. (1991): Intentionality and Truth: An Ethnographic Critique. unpublished manuscript, Department of Anthropology, University of Califomia, Los Angeles.

Flores, Fernando, M. Graves, B. Hartield and T. Wonograd. (1988): Computer Systems and the Design of Organizational Interaction. In ACM Transactions on Office Information Systems, Special Issue on the Language/Action Perspective. vol. 6, No. 2, pp. 153-172.

Foucault, Michel. (1979): Discipline and Punish: The Birth of the Prison. NY: Random House.

Garfinkel, Harold and Sacks, Harvey. (1970): On Formal Structures of Practical Action. In Theoretical Sociology, McKinney and E. Tiryakian eds. New York: Appleton-Century-Crofts, pp. 337-366.

Goodwin, Charles. (1981): Conversational Organization: Interaction between Speakers and Hearers. New York: Academic Press.

Goodwin, Charles and Goodwin, Marjorie. (1992): Assessments and the construction of context. In A. Duranti and C. Goodwin (eds.) Rethinking Context: Language as an interactive phenomenon. Cambridge, UK: Cambridge University Press, pp. 147-190.

Haraway, Donna J. (1991): Science as Culture, Science Studies as Cultural Studies? Paper prepared for the volume Cultural Studies Now and in the Future, P. Treichler, C. Nelson, and L. Grossberg (eds.), in prep., presented at a conference on Disunity and Contextualism: New Directions in the Philosophy of Science Studies. Stanford University, March 31-April 1.

Johnson, B., G. Weaver, M. Olson and R. Dunham. (1986): Using a computer-based tool to support collaboration: A field experiment. In Proceedings of the ACM Conference on Computer-Supported Cooperative Work, Austin, TX, pp. 343-352.

Levinson, S. (1983): Speech Act. Chapter 5 in Pragmatics. Cambridge, UK: Cambridge University Press.

Lynch, Michael. (1990): Pictures of Nothing? Visual Construals in Social Theory. Paper presented at the 85th Annual Meeting of the American Sociological Association, Washington, D.C., August.

Robinson, Mike and Bannon, Liam. (1991): Questioning Representations. In Proceedings of the European Conference on Computer-Supported Cooperative Work, Amsterdam, The Netherlands, pp. 219-234.

Sacks, Harvey. (1979): Hotrodder: A Revolutionary Category. In Everyday Language: Studies in Ethnomethodology, ed. G. Psathas, NY: Irvington, pp. 7-14.

Sacks, Harvey and Schegloff, Emanuel. (1979): Two Preferences in the organization of references to persons in conversation and their interaction. In Everyday Language: Studies in Ethnomethodology, ed. G. Psathas, New York: Irvington, pp. 15-21.

Schegloff, Emanuel (nd) To Searle on Conversation: A Note in Return. Prepared for a volume of essays in response to the work of John Searle, unpublished manuscript, Department of Sociology, University of California, Los Angeles.

Schegloff, Emanuel. (1972): Notes on a Conversational Practice: Formulating place. In Studies in Social Interaction, ed. D. Sudnow, New York, Free Press, pp. 75-119.

Schegloff, Emanuel. (1982): Discourse as an Interactional Achievement. In Analyzing Discourse: Text and Talk, ed. D. Tannen, Georgetown Roudtable on Language \& Linguistics, Washington, D.C.: Georgetown University Press, pp. 71-93.

Schegloff, Emanuel. (1988): Presequences and Indirection: Applying speech act theory to ordinary conversation. In Journal of Pragmatics, vol. 12, pp. 55-62. 
Suchman, Lucy. (1993): Technologies of Accountability: On Lizards and Aeroplanes. In G. Button (ed.) Technology in Working Order: Studies in work, interaction and technology. London: Routledge, pp. 113-126.

Winner, Langdon. (1986): Do Artefacts Have Politics? In The Whale and the Reactor. Chicago: University of Chicago Press, pp. 19-39.

Winograd, Terry and Fernando Flores. (1986): Understanding Computers and Cognition: A New Foundation for Design. Norwood, NJ: Ablex.

Wittgenstein, Ludwig. (1958): Philosophical Investigations. Oxford: Blackwell.

Yates, JoAnn. (1989): Control through Communication. Baltimore and London: Johns Hopkins Univesity Press. 